\title{
Poesia ao vivo: algumas implicações políticas e estéticas da cena literária nas quebradas de São Paulo
}

\author{
Carlos Cortez Minchillo ${ }^{1}$
}

A periferia está em toda parte ou a periferia é dentro da gente.

Binho

Em 23 de agosto de 2015, um domingo, mais de 15 adolescentes que iam da periferia do Rio de Janeiro em direção às praias da zona sul carioca foram retirados de um ônibus pela polícia militar e levados para averiguação. Segundo o que foi reportado pela imprensa, os jovens eram em sua maioria negros, e nenhum portava armas ou drogas. Aproximadamente um ano e meio antes, os rolezinhos tinham alarmado frequentadores e seguranças dos shopping centers em São Paulo, no Rio de Janeiro e em outras cidades brasileiras. Nesses "rolés", jovens de classe média baixa organizavam-se por meio das redes sociais e, em grandes grupos, reuniam-se buscando diversão, paquera e consumo, desestabilizando a normalidade anódina dos centros comerciais. Os rolezinhos acabaram sofrendo forte repressão policial, ganharam a mídia e foram parar na justiça, porque causavam confusão nas fronteiras traçadas a giz (mas vergonhosamente eficientes), que, em nome da proteção da sociedade "de bem", segregam as classes sociais nas cidades brasileiras, determinando, entre outras coisas, quem pertence a cada espaço público ou privado e quem deve ser mantido à margem, sob vigilância. Para Pedro Erber, os rolezinhos representariam uma forma de ocupar um espaço e "reclamar o direito à cidade, arrasada pela ocupação capitalista" (Erber, 2014, p. 23).

Menos do que combater a violência urbana que atinge todas as classes sociais (e que na verdade vitima especialmente os menos privilegiados), a triagem e rejeição de jovens de classes populares tenta inutilmente criar zonas francas, idealmente livres de pessoas e comportamentos indesejáveis ou ameaçadores. Parte da perversidade dos mecanismos explícitos ou implícitos de segregação e controle dos mais pobres reside justamente no fato de construir e pôr em circulação um discurso redutor sobre as relações sociais, que divide esquemática e artificialmente o território urbano e seus

1 Doutor em literatura brasileira e professor no Department of Spanish and Portuguese do Dartmouth College, Hanover, Estados Unidos. E-mail: minchillo@dartmouth.edu 
habitantes em dois setores supostamente uniformes e antagônicos. Com isso, reforçam-se expectativas estereotipadas e fobias, a partir da “discriminação por endereço" (Novaes, 2006, p. 106), que associa local de moradia a uma série de atributos como classe e status social, renda, poder de consumo, perfil racial, nível de escolaridade, comportamento. Dessa forma, o morador que vive na periferia, na favela, no conjunto habitacional, especialmente se negra ou negro, é associado a uma série de peculiaridades, como pobreza, carência, analfabetismo, ignorância, inadequação, inadaptabilidade, ameaça, periculosidade. A mídia, o cinema e a literatura têm muito a ver com a consolidação dessas identidades forjadas: em estudo sobre 258 romances brasileiros contemporâneos, por exemplo, constatou-se que as personagens negras são quase sempre pobres, e que $58,3 \%$ das personagens adolescentes negras do sexo masculino são bandidos ou contraventores (Dalcastagnè, 2008, p. 93-95). É digno de nota que o estudo aponte também que, em 93,9\% dos casos, essas representações literárias são da autoria de homens e mulheres brancos.

Daí o significado político e social da intensa movimentação cultural que tem surgido nas áreas periféricas das metrópoles brasileiras, onde, há mais de 15 anos, ativismo social e eventos artísticos estão, a despeito de condições quase sempre precárias, resgatando cidadania, fortalecendo autoestima, criando instituições e canais democráticos de expressão e favorecendo redes de sociabilidade por meio da música, do cinema, do teatro, do grafite e da literatura. Existem hoje inúmeros bairros periféricos que, graças a inciativas de moradores locais e, em alguns casos, à contribuição do poder público, abrigam bibliotecas e outros aparelhos culturais e hospedam projetos de produção e circulação artística, alterando para melhor certas condições materiais e colaborando para desconstruir a representação (e a autorrepresentação) preconceituosa, desesperançada e desumanizadora à qual essas áreas e seus habitantes foram historicamente reduzidos. ${ }^{2} \mathrm{O}$ poeta $\mathrm{e}$ apresentador de saraus Akins Kintê explica que "o desenho/que nos desenham/[é] sempre feio" (Kintê, 2014), mas seu colega, o escritor suburbano e agitador cultural Alessandro Buzo flagra a mudança:

\footnotetext{
${ }^{2}$ A respeito da reversão da imagem das zonas periféricas, ver, por exemplo, o documentário Acari cultural. Mapeamento da produção cultural em uma favela da Zona Norte do Rio de Janeiro, coordenado pela antropóloga Adriana Facina e dirigido por Arthur Moura e Felipe Xavier. Disponível em: <https://goo.gl/DoMW67>.
} 
Favelado com livro na mão, a contra indicação.

Pensavam que não sabíamos nem ler.

E aqui temos a prova

que estava errado quem duvidou.

Mais um livro (Buzo, 2013, p. 11).

A proposição alternativa do periférico como autor/leitor é um notável ponto de inflexão: corresponde, como nos rolezinhos, à tomada simbólica de um território - neste caso, o terreno da produção e consumo cultural no âmbito letrado, que sempre esteve associado a outros. "Crime, futebol, música/Eu também não consegui fugir disso", diz o rapper Mano Brown em "Negro drama" (Racionais MC's, 2002). De fato, a adesão à criminalidade, o dificultoso caminho do sucesso pelo futebol ou pela música, tanto quanto a ostentação pelo consumo, podem ser compreendidos como algumas das estratégias a que cidadãos de baixa renda (e não apenas eles) recorrem para se projetar socialmente, em resposta a anseios e necessidades pessoais, bem como a pressões da sociedade e da economia de mercado. À época da polêmica gerada pelos rolezinhos, o jornalista Leandro Beguoci chamou atenção para o fato de que a ostentação do consumo na periferia segue a mesma lógica que prevalece em toda a sociedade. Diz Beguoci: "pessoas que moram no limite de uma favela, mas não no seu coração, querem manter toda a distância possível das pessoas que moram nas áreas mais pobres daquela comunidade. Um emprego, uma roupa, tudo é uma marca de progresso, de ascensão" (Beguoci, 2014). Virar craque da bola ou astro do show business cumpre a mesma função. Ostentar, marcar, sinalizar: o consumo e o sucesso significam, são formas de linguagem que medeiam a autoimagem e as relações sociais. Da mesma forma, a violência é, segundo Luiz Eduardo Soares, uma "modalidade disciplinada de autorrealização, de produção de si e de relacionamento" (Soares, 2006, p. 126). Em todos os casos, trata-se da busca de meios de sobrevivência material e, simultaneamente, da produção de retratos positivos para si e para os outros.

Iniciativas sociais e discursos contra-hegemônicos, tendo origem nas próprias comunidades carentes ou periféricas, vêm recentemente diversificando o repertório disponível de imagens e referências que entram na construção identitária dos que vivem em zonas menos privilegiadas da cidade. Literatura também virou um tipo de "rolé", em que se ostenta papel, lápis, livro e voz, como canta com humor o poeta Daniel Minchoni em seu poema-canção "Literatura ostentação": 
literatura ostentação

essa é a meta, essa é a letra

a palavra bate forte

feito tiro de escopeta

sou poeta e os meus versos

fazem o que eu toco virar ouro

quando chego na biblioteca

as novinha já parte pro estouro

[...]

eu tenho que dizer uma parada

é pesada, eu também já li

os lusíadas no banheiro da balada

rei da biblioteca

também acho bonito relógio e corrente

mais importante é o que tá na sua mente

também acho bonito relógio e corrente

mais importante é plantar a semente (Minchoni, 2014a)

Minchoni recorre ao estilo musical e ao imaginário proposto pelo funk para reconstruí-lo desde dentro. Transformando literatura em sinal de status social, o poeta reestrutura os clichês do gênero musical (o apelo sexual e o sexismo, a louvação da criminalidade, do dinheiro e da ostentação) e reorganiza a escala de valores pela qual se orientam muitos jovens da periferia: "o mais importante é o que tá na sua mente". Também os Poetas Ambulantes adicionam uma alternativa às representações comumente associadas ao cidadão periférico. Ao recitarem e distribuírem poesias nos trens, ônibus e metrô da capital paulista, a cada nova intervenção, esses jovens poetas fazem um anúncio bem-humorado que parodia o discurso habitual dos pedintes e vendedores ambulantes:

Poderíamos estar matando, poderíamos estar roubando, poderíamos estar ouvindo som alto (sem fone), poderíamos estar dormindo, babando no seu ombro, mas não, estamos aqui, humildemente invadindo seu dia, para recitar e distribuir poesia. Agradecemos a compreensão de todos, tenham um bom dia! (Poetas Ambulantes, s.d.)

O ganho desse amplo fenômeno sociocultural é, em primeiro lugar, evitar que os habitantes da periferia sejam definidos e representados exclusivamente por discursos alheios. Em texto de 1949, no qual refletia 
sobre a poesia social, Carlos Drummond de Andrade notou que os poetas brasileiros, ao abordarem a figura do trabalhador, tendiam a retratos generalizados. Drummond atribuiu essa tendência à abstração dos escritores à sua pouca "familiaridade com os temas do trabalho" (Andrade, 1949, p. 1). O que Drummond não explicitou nessa ocasião é que esse desconhecimento de causa implicava uma questão de origem e inserção sociais: na sociedade brasileira, o escritor profissional tradicionalmente pertence a classes privilegiadas, é do sexo masculino e branco; no mais das vezes, ele só poderia tratar das questões do trabalhador de um ponto de vista distanciado. O que se vê agora, portanto, corresponde a uma tomada da bastilha discursiva: criaram-se condições para que as classes subalternas passem a agenciar a produção e a recepção de enunciados gerados no seio das próprias comunidades em que vivem. Como a bem-sucedida história da Rádio Favela e de outras rádios comunitárias indica desde os anos 1980, isso significa que os segmentos sociais menos privilegiados que moram na periferia ou na favela não estão sempre e necessariamente de olho no que se passa do "outro lado da ponte" ou no "asfalto". Tampouco são uma massa homogênea cuja existência se articula apenas em oposição a outra, a "dos ricos", "burgueses", "playboys". Nas suas experiências concretas, em seus desejos e em suas trocas simbólicas (Bourdieu, 1982), os habitantes da periferia, ainda que obviamente conectados com toda a malha social da cidade (por meio, por exemplo, das mídias eletrônicas e das relações produtivas, burocráticas e de consumo), mantêm estreito diálogo com a pluralidade de pessoas, instituições, valores e espaços de seu próprio entorno. É de lá que vem a sua linguagem e dicção; é também lá que está seu espelho, sua arena e sua passarela:

quando eu a vi

não foi amor ao primeiro olhar

a achava feia

constrangedora e vulgar

hoje eu entendo ela

e a gente que vive nela

sem vergonha de falar

como eu: "é nóis favela!" (Shabazz, 2011).

Deve-se sublinhar, ainda, que o compartilhamento de uma mesma realidade em muitos aspectos opressiva e insatisfatória, o enfrentamento de dificuldades e limitações comuns não poderiam 
jamais suprimir a diversidade humana desses ambientes periféricos e, com ela, as disputas de espaço e poder, as opções de ação e comportamento, as possibilidades múltiplas de performance identitária e de filiação ideológica, etária, ética, étnica e estética. Por isso, muitos textos da nova literatura marginal combatem comportamentos de indivíduos da própria periferia, como o consumismo, a opção pela criminalidade e o machismo, como no caso de Mariana Felix, que diz em homenagem às mulheres:

eu sou Pagu, já disse

não abro mão

não duvide que rebolo até o chão

mas se contenha

também sei a Constituição

que diz termos direitos iguais

então meça suas palavras

não sou obrigada as suas cantadas baratas, rapaz! (Felix, 2015a).

A mulher que sabe a Constituição, assim como o "favelado com livro na mão", de Buzo, o marginal escritor e o escritor marginal são figurações alternativas do cidadão marginalizado e é de se supor que possam reverter a histórica desvalorização simbólica dos espaços periféricos e de seus habitantes.

Aliás, a trajetória de vida de Alessandro Buzo, que conta ter deixado as drogas graças às perspectivas que as atividades culturais the proporcionaram, é em si mesma uma narrativa seminal e exemplar de superação pessoal. É mais um testemunho, entre tantos outros já disponíveis, da conquista de uma voz autoral para contar sua história, traçar o próprio retrato e mandar para o mundo o seu recado de um self made man, a despeito de todas as contrariedades e restrições que a vida periférica lhe impôs. Nas palavras de Ferréz, Buzo é um "virador de páginas tristes" $\mathrm{e}$ "tec[eu] o saber na viela do abandono [...] para fazerse ouvir no mundo" (Ferréz, 2014, p. 12). Mas o panteão da literatura periférica está também repleto de casos de escritores, ativistas e agitadores culturais que têm uma biografia mais integrada aos canais tradicionais de acúmulo de capital cultural: a escola, a universidade, o trabalho acadêmico. São professores, historiadores, cientistas sociais, jornalistas cuja legitimidade de discursos e ações deriva não só de sua formação escolar mas também do fato de terem crescido e vivido na favela ou na "perifa". Eles são a prova viva da diversidade desses 
espaços marginais, que abrigam uma pluralidade de narrativas de vida, nem todas condenadas à ameaça, abandono e marginalização, como sugere o depoimento da escritora Claudia Canto:

Nunca fui da margem... Pode ser à margem porque eu estava fora do circuito cultural, intelectual e tal, eu estava afastada do centro, mas eu nunca estive à margem, eu sempre me joguei no circuito, eu pegava as peças gratuitas de teatro [...] eu acho que eu fui uma privilegiada, eu pude estudar, eu pude me dedicar à leitura, eu pude ir ao teatro, eu pude fazer tudo isso (apud Nascimento, 2009, p. 119).

A aposta é que a revitalização de um locus de enunciação periférico tenha o potencial de alterar em alguma medida as relações de poder na sociedade, já que pode reconfigurar a crença em quem tem a "legitimidade das palavras" para manter ou subverter a ordem (Bourdieu, 2007, p. 15). Legitimidade que nasce e se alimenta do sentimento fortalecido de pertencimento e de uma utopia enraizada no território marginal: "[a] gente não quer mudar da periferia, e sim mudar a periferia” (Vaz, 2008, p. 227). Legitimidade que pode melhorar a relação afetiva com o espaço em que se vive e a partir do qual se espera combater as relações opressivas de poder: "Vamos tomar a casa-grande de assalto/Poeta suburbano, colocando a periferia lá no alto", declama Clayton Mendes em uma sessão do Sarau Suburbano Convicto (Mendes, 2015). Legitimidade para, recusando as classificações que desabonam o cidadão, reafirmar a liberdade e o orgulho de se ser o que se é, como faz o poeta Germano Gonçalves Arrudas, em "Favela sim senhor":

ninguém embaça na minha raça

pois com ela sou quem quero

não tem patrão, polícia ou clero

que defina esse menino

sou nordestino, sou banto

sou dos cantos do Espírito Santo

miliano paulistano mulçumano

e eu só tenho a agradecer a esses genes misturados

pelos meus antepassados

que fazem do meu existir essa grande miscelânea

essa energia espontânea que corre nas minhas veias (Arrudas, 2014) 
Indicativas do caráter revolucionário do discurso produzido na periferia são também as imagens, recorrentes na literatura marginal ${ }^{3} \mathrm{e}$ nas letras de rap, que fundem literatura e violência. Nesse campo de produção, a metáfora da escrita/leitura como armamento ou munição é um tropos poderoso, que ressignifica tanto o gesto de afronta ou crime, quanto a função da literatura: 85 letras e um disparo é o título de um dos livros do escritor Sacolinha (Ademiro Alves de Sousa) e, na mesma linha, o poeta Vagner Sampaio recita no Sarau da Cooperifa o verso "eu tô armado com um livro na mão" (Itaú Cultural, 2012). A literatura vista por esse prisma é indissociável da função política, e a violência, agora discursiva, tem como fim combater as desigualdades sociais e, por fim, a própria violência física. Sérgio Vaz, na narrativa que escreveu para contar sua trajetória de morador, poeta e agente cultural na periferia de São Paulo, recorre à ironia para integrar em seu texto as ideias de literatura e violência, distorcendo o discurso hegemônico sobre a periferia (o lugar do crime, das drogas) por meio da introdução de novos hábitos (leitura). Resulta um retrato documental ambíguo, que confirma e ao mesmo tempo subverte a imagem de periferia que se projeta para toda a sociedade:

A periferia nunca esteve tão violenta, pelas manhãs é comum ver, nos ônibus, homens e mulheres segurando armas de até quatrocentas páginas. Jovens traficando contos; adultos, romances. Os mais desesperados cheirando crônicas sem parar. Outro dia um cara enrolou um soneto bem na frente da minha filha (Vaz, 2008, p. 117).

Como se focaliza aqui um processo de apropriação de voz, de perspectiva e de produção e recepção de discurso, não espanta que a literatura ocupe papel de destaque nessa redistribuição de poder

\footnotetext{
${ }^{3}$ Os termos "literatura periférica" e "literatura marginal" não são consensuais entre os escritores de que estamos tratando. Para alguns, se entendida em sentido geográfico, "periferia" não dá conta da abrangência espacial do fenômeno dos saraus e slams, que ocorrem em diferentes áreas pobres inclusive centrais - espalhadas pelas cidades; a polissemia de "marginal", por sua vez, pode gerar mal-entendidos: seja por sua associação com o universo do crime, seja pelo emprego de "marginal" para designar a literatura, especialmente a poesia, produzida no contexto da contracultura e de oposição ao regime militar brasileiro a partir dos anos 1970. Para uma discussão dessa terminologia, ver Patrocínio (2013, p. 23-39) e Nascimento (2009, p. 36-49). Por ambos os termos captarem o mesmo fenômeno de ângulos diferentes, mas não antagônicos, e por sua equivalência em vários estudos sobre o assunto, para os fins deste trabalho emprego indistintamente as expressões "literatura periférica" e "literatura marginal".
} 
simbólico. Até porque, comparada a outras modalidades artísticas, a literatura se viabiliza com menores custos e menos recursos tecnológicos, especialmente se a circulação do texto literário se faz pela performance ao vivo ou por meio da internet, como efetivamente vem acontecendo. Esse aspecto é ainda mais importante quando as verbas públicas são escassas e o dinheiro no bolso do cidadão é curto, como ocorre nos meios periféricos. Isso talvez explique em parte a abrangência e vitalidade atual da cena literária marginal em uma metrópole como São Paulo, onde semanalmente ocorrem dezenas de saraus literários e competições de poesia (poetry slams). Em texto de 1998, antes mesmo da disseminação dos eventos literários periféricos no início do século XXI, Heloísa Buarque de Hollanda já comentava o "número crescente de poetas provenientes de bairros de periferia ou subúrbios de baixa renda" e detectava uma certa recomposição no sistema literário, pela associação entre poesia, performance e mídias eletrônicas:

$\mathrm{O}$ emergente mercado da poesia falada tende a democratizar o consumo de poesia e abrir enormes possibilidades para a redistribuição da fala do poeta num espaço público mais amplo. A poesia estaria começando a tender na direção de uma culturalização, ou seja, uma inédita ampliação de seu raio de consumo através da abertura de espaços culturais não formais e da emergência de novos hábitos sociais e comportamentais (Hollanda, 2001, p. 15).

As proporções que a voga de eventos de performance literária tomou de lá para cá é ainda mais surpreendente, porque se dá num período em que, paradoxalmente, dada a concorrência dos meios eletrônicos, temese a morte dos livros, repetidamente se lamenta o desinteresse histórico dos brasileiros pela literatura e se condena, como sempre, o suposto descuido com o uso da língua portuguesa. Frente a tudo isso, é uma grata surpresa constatar que a poesia esteja soltando a voz em inúmeros saraus e slams pelo Brasil afora. Interessa-nos refletir sobre algumas funções e implicações - sociais, políticas e propriamente literárias dessa insistente presença da literatura pela cidade. O que os textos e seu modo de produção e fruição por estratos subalternos da população podem revelar? Sem a pretensão de dar conta de uma cena cultural tão diversa e dispersa, apresento aqui algumas tomadas parciais a partir de uma observação necessariamente lacunar do circuito de eventos literários periféricos na cidade de São Paulo. 


\section{Saraus e slams: literatura na voz e no corpo (mas não só)}

Uma enfiada de nomes pode dar uma melhor ideia da extensão atual das atividades literárias nas "quebradas" de São Paulo: Sarau do Binho, da Cooperifa, da Brasa, da Madrugada, da Roça, da Educação e Cultura, da Vila Fundão, do Beco, do Pipa, do Vinil, do Burro, de Paraisópolis, Suburbano Convicto, Poesia na Brasa, Sobrenome Liberdade, Palmarino, Elo da Corrente, no Kintal, Carolina, Maria Sem Vergonha, Literatura Nossa, Beco dos Poetas, Preto no Branco, Encontro de Utopias, Militantes, Mesquiteiros, Sarauzim. Zap! Slam, Slam Resistência, Comungar, do Grito, do 13, do Corre, Slam da Guilhermina, da Ponta, Menor Slam do Mundo.

Além de saraus e slams de poesia, ocorrem intervenções poéticas em transportes públicos, como as dos Filhos de Ururaí e dos já mencionados Poetas Ambulantes. Os saraus costumam ser semanais; os slams de poesia, mensais, e muitos poetas e ouvintes circulam, a cada semana, por vários desses eventos, que têm características e personalidades próprias, mesmo quando seguem modelos de organização semelhantes (Tennina, 2003, p. 21 ss.). Muitos frequentadores, alguns deles há $\operatorname{anos}^{4}$ fiéis a esses encontros em bares, livrarias, praças, estações do metrô, "transitam de um bairro a outro sem levar em consideração as grandes distâncias geográficas, nem as distâncias que impõem a realidade do tráfico e da pobreza" (Tennina, 2013, p. 13). O número de participantes pode variar bastante, mas, apenas para se registrarem alguns parâmetros, a média de público do Sarau da Cooperifa (um dos mais conhecidos e frequentados) é de 250 pessoas, segundo o escritor e host Sérgio Vaz (Vaz, 2008, p. 127). No sarau Suburbano Convicto, liderado por Alessandro Buzo e que acontece no bairro do Bexiga, em média 20 a 35 poetas se apresentam a cada terça-feira (Buzo, 2015, p. 9). O Slam da Guilhermina, por sua vez, reúne a cada última sexta-feira do mês um público de cerca de 100 pessoas ao lado de uma estação de metrô na zona leste (Albertoni e Fagundez, 2015).

Saraus e slams coincidem naquilo que têm de mais básico: ambos reúnem apresentadores e espectadores num evento de portas abertas (muitas vezes, literalmente, a céu aberto), com a finalidade primeira de

\footnotetext{
${ }^{4}$ Os precursores são a Noite da Vela, criada em 1995 pelo poeta Binho e que, em seguida, foi substituída pelo Sarau do Binho (2004), e o Sarau da Cooperifa, criado em 2001 pelo poeta Sérgio Vaz. Zap!Slam - Zona Autônoma da Palavra, criado pelo Núcleo Bartolomeu, é, segundo pude apurar, o primeiro slam em São Paulo e iniciou suas atividades em 2008.
} 
elocução e apreciação ao vivo do texto literário, em especial a poesia. Ainda que os estilos e qualidade das performances variem muito, esses eventos põem em relevo o que está sendo dito e o modo como está sendo circunstancialmente apresentado: mais que um fenômeno de oralidade, em que se ressaltam qualidades propriamente acústicas e rítmicas, tratase de um acontecimento em que a fala e a escuta estão permeadas pela gestualidade, linguagem facial, indumentária, peculiaridades do ambiente em que ocorrem e pela conexão emocional estabelecida entre artista e público ao longo da performance (Zumthor, 1997).

Sem muitas regras que disciplinem a entrada e a permanência dos participantes durante o evento, aqueles que desejam apresentar um texto realizam a inscrição com o mestre de cerimônia ou seus auxiliares no início das atividades. Normalmente, o limite em cada sessão de sarau (ou em cada rodada do slam) é de um texto por apresentador, cuja performance não deve ultrapassar alguns poucos minutos. Enquanto um autor apresenta seu texto, todos os demais presentes constituem a audiência, num rodízio de papéis que tem sido apontado como um dos elementos democráticos dos saraus e slams, onde qualquer um pode assumir temporariamente o centro do espetáculo, sob o compromisso implícito e voluntário de acolher e fruir as demais performances. A recepção se caracteriza não só pelo silêncio que geralmente predomina durante a apresentação de cada texto, mas também pelas manifestações de interação por parte da audiência - gritos, assobios, risos, palmas que usualmente integram o evento performativo.

Os slams se diferenciam dos saraus por seu caráter competitivo. No mundo dos jogos de cartas e de esportes como tênis e golfe, slam (ou mais propriamente grand slam) refere-se à vitória de um mesmo jogador em uma sequência de torneios. A transposição do termo para o universo literário se deu provavelmente em 1986, quando o trabalhador da construção civil e poeta norte-americano Marc Smith criou o Uptown Poetry Slam, uma competição semanal de poesias nas noites de domingo no clube de jazz Green Mills, em Chicago (Somers-Willett, 2009, p. 3-4). $\mathrm{O}$ formato que Smith imprimiu orienta ainda as incontáveis "comunidades slams" que existem ao redor do mundo e que, em muitos casos, são certificadas por uma organização sem fins lucrativos, a Poetry Slam Inc. As regras mais importantes de um slam dizem respeito à autoria, à forma de apresentação e de avaliação. O texto deve ser composto pelo apresentador, ainda que citações e samplings sejam 
permitidos. O tempo de apresentação de cada poeta não deve ultrapassar três minutos. Não se pode usar nenhum instrumento musical ou elemento cênico, como cenário ou figurino. Os jurados, geralmente em número de cinco, são escolhidos no início do slam entre pessoas da audiência que, ao final da apresentação de cada poema, dão notas de 0.0 a 10.0. Só os vencedores de cada rodada prosseguem à etapa seguinte da competição; apresentam um novo texto a cada etapa, até que na última rodada (geralmente a terceira), sai o grande vencedor do dia, que pode receber como prêmio livros, CDs ou mesmo dinheiro. Certos poetas e poetisas fazem uma carreira bem-sucedida nos circuito slam da cidade e tornam-se atrações especiais, chegando a competir em outros estados e países (Stella, 2015). Por atraírem público com a qualidade de suas performances, aumentando o prestígio do slam, esses poetas e poetisas destacados chegam mesmo a ser remunerados pela participação. Para alguns críticos que têm analisado o slam poetry nos Estados Unidos, o formato de programa de auditório pode reduzir os slams a um entretenimento divertido, banalizando a experiência literária e anulando a carga crítica dos poemas, que predominantemente condenam o "sistema", a manipulação ideológica da mídia, os preconceitos e a mercantilização capitalista (Hoffman, 2011, p. 204-205).

Do ponto de vista dos estudos literários, a mais evidente novidade desses eventos reside no caráter radicalmente performático da literatura que aí se produz e se consome, assim como a articulação entre os eventos ao vivo e suportes eletrônicos ou impressos. Saraus e slams converteram para ambientes populares e democráticos de hoje práticas literárias coletivas, de cunho aristocrático ou burguês, que há muito haviam caído em desuso e nas quais o texto lido, cantado ou declamado de memória ocupava o centro de interesse. Ao fazê-lo, também podem ser associados à arte dos repentistas populares que, individualmente ou em pares, com seus improvisos, declamações e disputas poéticas animam ainda hoje feiras e festas de tantos recantos do Brasil. Isso é especialmente verdadeiro no caso dos slams, que reinstauram dessa tradição popular o caráter de competição e desafio. Mas é com o hip-hop que saraus e slams conectam-se de forma mais nítida (Nascimento, 2009, p. 92-97; Silva, 2012, p. 31-43). A dimensão política, gregária e identitária de toda a cultura hip-hop em torno de práticas de expressão, conscientização e resistência das camadas marginalizadas de jovens urbanos é a matriz dos eventos literários periféricos. No âmbito estético, 
vêm do rap muitos dos elementos que caracterizam as performances de poesia "nas quebradas" metropolitanas: a gestualidade e a ginga corporal; o texto rimado e o canto, marcadamente compassado, que, ao enfatizar o ritmo em detrimento da melodia, simula e ao mesmo tempo reinventa a fala coloquial (Attridge, 1995, pp. 90-94).

A centralidade da performance afeta a produção e a fruição da literatura, assim como os modos tradicionais de estudá-la. Para Susan Somers-Willett, a apresentação ao vivo de poesia não pode ser reduzida à oralidade e à escuta, mas consiste numa "experiência multisensória", na qual o público experimenta como o poeta "incorpora fisicamente o poema" (SomersWillett, 2009, p. 17). Note-se ainda que "poesia ao vivo" quase nunca é essencialmente espontânea, mas é a convergência de trabalho prévio do poeta e de fatores circunstanciais no calor da hora: de um lado, produção de texto, planejamento e ensaio da performance; de outro, a atualização do texto/roteiro/coreografia no espaço-tempo da apresentação diante de uma audiência específica (Schechner, 2006, p. 28). A poetisa Mariana Felix, bem conhecida no circuito dos slams de São Paulo, afirma que escreve seus poemas consciente das possibilidades de performance, planejando antecipadamente pausas e gestos. ${ }^{5}$ Daniel Minchoni, por sua vez, descreve as complexidades do processo de criação quando o texto nasce ou é destinado à apresentação diante de uma plateia:

Prefiro criar ao vivo. Oralmente. Geralmente chego num sarau, com uma ideia na mão e nada na cabeça, e faço ali, de improviso. E vou acertando o voo do carcará peneirando. Vou falando várias vezes até formatar pela memória e o que ficar ficou. Mas também sento a bunda pra ler e quando leio tenho vontade de escrever. E aí é o velho processo: leitura e lapidação. Tem coisa que escrevo meramente pra documentar, pois como foram criados pra ser apresentados não funcionam [na forma escrita]. Do mesmo jeito que transformo muitos textos em performance distorcendo e deturpando. Sem dó nem piedade. Sem apego. Crio como der. O que não pode é encostar (Minchoni, 2014b, grifo nosso).

Desses depoimentos deduz-se que a "poesia evento" tem personalidade própria, distinta da poesia "meramente" escrita, contando com recursos específicos e requerendo diferentes estratégias de composição. Até porque, especialmente no caso dos

\footnotetext{
${ }^{5}$ Informação verbal obtida em conversa pessoal com o autor.
} 
poetas dos slams, seduzir o público pela forma como se apresenta ao vivo o poema é a chave do sucesso e a condição para a permanência nos torneios e para aumentar o prestígio entre os demais escritores e entre o público. Contudo, nada está mais longe da verdade do que imaginar que a poesia para performance sempre independa - ou mesmo pretenda independer - do registro escrito. Primeiramente porque ainda que improvisos ocorram, a maioria dos poetas dos saraus e slams produz seus versos antecipadamente e, se a maior parte os decora para o momento da performance, há alguns que optam por ler seus poemas, principalmente nas primeiras vezes que os encenam. Em segundo lugar, mesmo para aqueles que frequentam o circuito da spoken word e ali obtêm notoriedade, a publicação em livro ainda preenche expectativas autorais que correspondem a parâmetros hegemônicos de prestígio no sistema literário. ${ }^{6}$ É assim que, sem que se comprometa o ambiente democrático desses eventos literários, parece manter-se uma certa hierarquia entre poetas baseada em distintos critérios: idade, tempo "de casa", frequência de participação e, talvez o mais importante para a clivagem das "celebridades", o trunfo da publicação em livro. O mais interessante é que, para os envolvidos, aparentemente não há desconexão ou antagonismo entre a poesia ao vivo e o registro impresso. O sarau Suburbano Convicto talvez seja a expressão mais evidente disso, já que nasceu de uma livraria especializada em literatura marginal, que se mantém até hoje, apesar das dificuldades. De acordo com Buzo, "o Sarau Suburbano acaba se a livraria fechar". O escritor acrescenta ainda: "nosso maior orgulho é os poetas e escritores que frequentam a casa e têm livro na prateleira" (Buzo, 2015, p. 10-11).

A conexão dos saraus e slams com a escrita também se verifica nos meios eletrônicos. Assim como os rolezinhos e as recentes manifestações sociais de rua, os eventos literários parecem ganhar impulso, em grande medida, por meio das mídias sociais. Blogs e páginas no Facebook conferem-lhes visibilidade e como que uma sobrevida, reforçando os laços comunitários entre os frequentadores (que se tornam "amigos" no Facebook, por exemplo) e disponibilizando muitas vezes vídeos, de modo

\footnotetext{
${ }^{6}$ Nesse aspecto, os poetas performáticos dos saraus e slams não destoam do padrão geral da literatura marginal. O estudo de Érica Peçanha do Nascimento indica que os escritores da literatura periférica brasileira contemporânea compartilham o desejo de publicação impressa (Nascimento, 2009, p. 49 e p. 91$).$
} 
a formar, mesmo que de maneira incompleta, dispersa e aleatória, um arquivo de performances que, de outra maneira, facilmente se perderiam. Vale notar incidentalmente que essa vibração literária na internet, calcada em eventos no mundo real, difere em muito das previsões de há 20 anos, quando se apostava em narrativas hipertextuais, poemas animados ou $e$ books como os formatos mais promissores e inovadores da incorporação da literatura ao mundo virtual.

Quanto à observação e ao estudo acadêmico dessa literatura performática, surge para o crítico uma série de exigências e entraves, comuns aos estudos de teatro e de performance lato sensu. Obviamente, para se compreender o que acontece em saraus e slams, a análise do texto impresso não basta, porque apaga toda a complexidade situacional envolvida nas performances. Ademais, está disponível em meio impresso ou eletrônico só uma parcela diminuta dos textos que se apresentam semanalmente nos muitos eventos que se espalham pela cidade. Mesmo os vídeos disponibilizados na internet cobrem bem pouco do total das apresentações e muitas vezes registram exclusivamente a performance do texto literário, apagando o contexto mais geral do evento em que ela se inseriu, como as introduções do mestre de cerimônias e reações do público. Por tudo isso, o estudo dessas novas instâncias do discurso literário deve confrontar-se, e talvez conformar-se, com textos (no sentido literário e semiótico) que são essencialmente instáveis e fugazes. Esse problema, digamos, "técnico", esbarra também em interessantes questões sobre a ética do acercamento investigativo em torno do objeto "literatura marginal". Para estabelecer um arquivo pessoal, o investigador talvez tenha de optar pelo registro em vídeo durante as apresentações. Essa alternativa, no entanto, pode comprometer um dos fundamentos dos saraus e slams: o estabelecimento de conexão comunitária entre os presentes. Ao evidenciar sua situação de investigador, o acadêmico talvez reforce o seu provável "não pertencimento", o que pode causar reações de desconfiança sobre a legitimidade da sua presença e da apropriação da realidade e das representações marginais a partir de instituições que lhes são estranhas, como a universidade. Entende-se essa relutância (ou mesmo aversão): a ideia que sustenta o conceito de literatura marginal contemporânea é o imperativo político de falar de própria voz. Como diz o poeta e rapper Dugueto Shabazz, "o título do meu depoimento é nós por nós/meu sofrimento não será mestrado de 
playboy" (Shabazz, 2007). ${ }^{7}$ No contexto da "poesia ao vivo" nas áreas periféricas, a natureza performática das apresentações apoia-se geralmente num elemento sociocultural de primeira importância, qual seja, a legitimidade ou autenticidade do poeta, ancoradas por seu pertencimento ao grupo social. Nesse aspecto, os eventos literários periféricos "acionam uma série de complexidades culturais e políticas antes mesmo de o autor abrir sua boca" (Somers-Willett, 2009, p. 18).

\section{Eu por nós; nós contra eles}

Por privilegiar o contato presencial entre escritores e audiência, os eventos literários contemporâneos fomentam uma rede de sociabilidade e convívio que destoa radicalmente do paradigma usual de literatura como atividade individual e solitária de escrita e leitura. Em "Disappearing ink: poetry at the end of print culture", Dana Gioia defende que a cultura impressa perde sua supremacia nas comunicações e que a mais importante revolução na literatura norteamericana recente teria sido a emergência de uma poesia que independe do papel, especialmente aquela que circula por meio da voz e do corpo do performer (Gioia, 2003, p. 25). A literatura apresentada ao vivo é confraternização pela palavra. No Slam da Guilhermina, os frequentadores são chamados amigavelmente de Guilhermanos e Guilherminas, concedendo a todos os presentes uma certidão de pertencimento à localidade onde o evento acontece. Nesse mesmo slam, Mariana Felix apresentou um poema em que nomeia e louva vários companheiros dos encontros poéticos, revelando a existência de uma verdadeira confraria entre os seus habitués (Felix, 2015b). No Sarau do Suburbano Convicto, é praxe que, ao chegar, cada frequentador cumprimente os demais, conhecidos ou não, com um aperto de mão. Na minha experiência em uma sessão do Slam do Grito, esse costume também pôde ser observado. Acima de tudo, o que os saraus e slams da periferia propõem - ainda que em princípio garantam total liberdade temática e ideológica - é um comprometimento político comunitário, um exercício coletivo de emancipação das vozes subalternas e a luta das comunidades pela

\footnotetext{
${ }^{7}$ Paulo Roberto Tonani do Patrocínio desenvolve um estudo consistente sobre essa questão no último capítulo de seu livro (Patrocínio, 2013, p. 225-246).
} 
superação de seus traumas e problemas. Não à toa, o movimento de "poesia falada" nas periferias, assim como a cena hip-hop que lhe deu alento, mantém estreitos laços com organizações e projetos de ativismo social e acolhem reivindicações de grupos subalternos como negros e imigrantes. O brasileiro-boliviano Bryan Rodriguez, poeta slam e rapper, é um dos agitadores culturais da comunidade de imigrantes latino-americanos de São Paulo. Ele incorpora e compartilha em seus textos as experiências de rechaço sofridas por integrantes de seu grupo social:

Te cuento una vez me paró un puto "poli" diciendo:

- Volve a tu país!

$\mathrm{Al}$ infierno de donde saliste. [...]

Depende de la marca que vistes, dejara marcas en tu cuerpo.

Por el hecho que soy boliviano. No por ser extrangero

Si yo fuera norteamericano ya estarían chupándome los huevos.

De nuevo y de nuevo es la misma mierda de historia,

Pero que carajos tendrá esa gente en la mente que tanto a mi gente odia.

Será fobia, el miedo de aceptar que no son mejores (Rodriguez, 2015)

Segundo Bryan, a própria comunidade de imigrantes bolivianos não está necessariamente interessada em sua música e sua poesia, ${ }^{8}$ mas isso talvez só aumente o papel das comunidades de literatura e rap, que acolhem com especial empatia a diversidade entre autores periféricos e podem ajudar a galvanizar as demandas de cada um, promovendo suas mensagens políticas. Por isso, os saraus e slams são importantes não apenas pelos textos apresentados, mas, sobretudo, pela dinâmica de sociabilidade que propõem: por garantirem livre acesso e participação (que se resume no conceito do open mike - o microfone franqueado a todos), e por adotarem um ethos de tolerância e respeito pela diversidade, tais eventos assumidamente pretendem fomentar práticas democráticas e descentralizadoras. É no modus operandi que reside muito da força emancipatória da literatura marginal. Inclusive em relação aos poderes constituídos dentro do próprio campo literário, porque os saraus e slams descartam uma série de arraigados mecanismos de valoração, hierarquização e chancela das comunidades interpretativas (Fish, 1980) que regulam (e cerceiam) a circulação da literatura, graças

\footnotetext{
${ }^{8}$ Informação verbal obtida em conversa pessoal com o escritor.
} 
ao controle de indivíduos e instituições cujo poder e autoridade são reconhecidos nas esferas mais influentes da sociedade. Vale lembrar que nos slams a pontuação de cada apresentação é decidida por jurados aleatoriamente selecionados entre a plateia. Assim, apesar do caráter de entretenimento que possam assumir, o contexto em que se criaram e seus pressupostos ideológicos fazem dos eventos literários das quebradas algo mais consequente que um programa de calouros ou um "MasterChef" da literatura. Ocupando espaços físicos alternativos, normalmente imunes às pressões comerciais ou ao patronato político, saraus e slams reafirmam um "nós" em oposição a um outro, para desconstruir percepções equivocada e atitudes violentamente opressivas. Nesse embate, defendem o direito ao corpo, ao espaço, à revisão da história, como se lê no trecho do belo poema "Duro não é o cabelo", de Akins Kintê:

Por tê-lo e por ser belo

O cabelo

Querem zero, ou prendê-lo

Às vezes o quero

E o barbeiro amarela

Na dele

Naquelas

Sem atitude, sem negritude

O branquela

Não entende crespitude

Racismo

É engodo e sequela

Engorda os de lá

E os de cá esfarela

Zelo o crespo com fulgor

Negro zela com amor

Pra entendê-lo

Berro, quirela

Enterro aquela falsa abolição

Exijo mais pente afro

Menos ferro, menos favela

Mais terra e condição

Que duro não é o cabelo

São as escolas e suas deixas

O sistema e suas brechas

[...] 
Já foi dread o meu cabelo

Vinha na minha

Ao vê-lo

O playboy não se continha

Tô mentindo?

Quer farinha

Quer maconha

Quer balinha

A patricinha

Confundiu-me com tráfico

Com furto

Pela pele pelo cabelo

Compreendê-los como? (Kintê, 2014)

Kintê lança mão de uma metonímia (o cabelo) como trincheira simbólica para travar uma batalha de imagens. Daí que parta de uma negação ("duro não é”), revogando em seguida os estereótipos com que o negro é identificado (traficante, criminoso) e reafirmando sua identidade e sua beleza afro: sua crespitude. Como estratégia de combate, muitos poemas da literatura periférica seguem o padrão de Kintê ao dividir as vozes do poema entre "os de cá" e "os de lá" e, nesse aspecto, talvez reforcem a lógica segregacionista que regula a sociedade brasileira. Nessa cartografia simbólica gerada a partir da perspectiva da periferia, o branquela, o playboy, a patricinha fazem parte do "sistema" que oprime e que tem a seu favor a brutalidade policial, a mídia mistificadora, o poder do dinheiro e a corrupção política. Na divisão esquemática reside a força e a debilidade da mensagem dos textos que costumam circular nos saraus e slams. Pode-se questionar o caráter abstrato e generalizador e a falta de matizes desses retratos do outro socialmente privilegiado. Mas é fácil compreender que esse discurso revoltado surja como resposta - um berro coletivo - contra uma postura igualmente simplista e generalizante que há muito vem ofendendo, segregando e matando os integrantes das comunidades marginalizadas. Como evitar esse curto-circuito de imagens estereotipadas sem que se perca a carga reivindicatória das vozes subalternas? A literatura marginal poderá inventar uma outra relação entre classes numa sociedade francamente desigual?

Outro dilema consiste em como manter o caráter alternativo e autêntico da literatura periférica num sistema cultural que tende a 
transformar qualquer produto, mesmo os contra-hegemônicos, em commodities. A veiculação de saraus e slams na grande mídia, o patrocínio que às vezes recebem do poder público e de empresas (slams no espaço Red Bull em São Paulo, por exemplo) e sua inclusão em eventos culturais mainstream como a Festa Literária Internacional de Paraty (Flip) atestam o êxito das performances literárias marginais e, ao mesmo tempo, representam ameaça ao complexo de práticas e valores comunitários que as engendrou. É possível que o caráter contestatório dos eventos de "poesia ao vivo" esteja se tornando palatável para além das comunidades periféricas pari passu à sua apropriação por agentes políticos, culturais e comerciais. Ao transpor os territórios onde se situam o "nós", ao incluir outras audiências entre "eles", a performance nos saraus e slams fatalmente se altera. Se tal tendência se efetivar, será necessário averiguar que vozes permanecerão ressoando nesses eventos "pós-periféricos" e se, nas comunidades de origem, saraus e slams continuarão a fortalecer a consciência de laços históricos, sociais e culturais graças à apropriação e inovação dos meios de expressão e apreciação literária. Isso porque, definitivamente, o valor da literatura marginal periférica não se esgota no que dizem as palavras. Quem, onde, com quem, de que modo: nos saraus e slams o texto só manda o seu recado e só mostra sua relevância sócio-política quando embebido no fluxo vivo das circunstâncias.

\section{Referências}

ALBERTONI, Natália; FAGUNDEZ, Ingrid (2015). Iniciativas de cidadãos e empresas levam mais paulistanos a ocupar SP. Folha de S. Paulo, São Paulo, 26 jul. Disponível em: <http://goo.gl/BTa5Ga>. Acesso em: 3 set. 2015.

ANDRADE, Carlos Drummond de (1949). Trabalhador e poesia. A Manhã, Rio de Janeiro, Suplemento Letras e Artes, 11 set.

ARRUDAS, Germano G. (2014). Favela sim senhor. Apresentação no I Festival de Poesias da Cidade de São Paulo, organizado pelo coletivo Correspondência Poética. Vídeo. Disponível em: <http://goo.gl/7civ80>. Acesso em: 9 set. 2015.

ATTRIDGE, Derek (1995). Poetic rhythm: an introduction. Cambridge: Cambridge University Press.

BEGUOCI, Leandro (2014). Os debates extremados à direita e à esquerda estão ignorando as pessoas que participam do rolezinho. É hora de entender a 
periferia. Notícias do Instituto Humanitas Unisinos, São Leopoldo, 21 jan. On-line. Disponível em: <http://goo.gl/38COqL>. Acesso em: 19 jul. 2016.

BOURDIEU, Pierre (1982). A economia das trocas simbólicas. 2. ed. São Paulo: Perspectiva.

BOURDIEU, Pierre (2007). O poder simbólico. Tradução de Fernando Tomaz. 10. ed. Rio de Janeiro: Bertrand Brasil.

BUZO, Alessandro (Org.) (2013). Poetas do sarau Suburbano. São Paulo: Edicon, v. 2. BUZO, Alessandro (Org.) (2015). Poetas do sarau Suburbano. São Paulo: Edicon, v. 3. DALCASTAGNÈ, Regina (2008). Entre silêncios estereótipos: relações raciais na literatura brasileira contemporânea. Estudos de literatura brasileira contemporânea, Brasília, n. 31, p. 87-110, jan./jun.

ERBER, Pedro (2014). The politics of strolling. In: INTERNATIONAL CONGRESS OF THE LATIN AMERICAN STUDIES ASSOCIATION - LASA, 32., May 21-24, 2014, Chicago, IL. Papers... Pittsburgh: Lasa. Texto enviado por e-mail pelo autor.

FELIX, Mariana (2015a). Marias. Publicação da autora em sua página pessoal no Facebook. São Paulo, 10 ago. Vídeo. Disponível em: <https://goo.gl/GfnKlu>. Acesso em: 22 ago. 2015.

FELIX, Mariana (2015b). Sob a luz do lampião - Fragmentos poéticos: 2015 I. Vídeo da participação de Mariana Félix no Slam da Guilhermina, dez. 2014. São Paulo, 24 jan. On-line. Disponível em: <https://goo.gl/jMEUdT>. Acesso em: 12 set. 2015.

FERRÉZ (2014). Sem tantas vírgulas e sem limites. In: BUZO, Alessandro. Favela toma conta 2: a literatura e o hip-hop transformaram a minha vida. São Paulo: Edicon, p. 11-12.

FISH, Stanley (1980). Is there a text in this class? The authority of interpretative communities. Cambridge: Harvard University Press.

GIOIA, Dana (2003). Disappearing ink: poetry at the end of print culture. The Hudson Review, New York, v. 56, n. 1, p. 21-49, Spring.

HOFFMAN, Tyler (2011). American poetry in performance. Ann Arbor: University of Michigan Press.

HOLLANDA, Heloísa Buarque de (2001). Introdução. In: HOLLANDA, Heloísa Buarque de. Esses poetas: uma antologia dos anos 90. Rio de Janeiro: Aeroplano, p. 9-21. 
ITAÚ CULTURAL (2012). Sérgio Vaz - Sarau da Cooperifa - Jogo de Ideias (2008). Entrevistas ao jornalista Claudiney Ferreira, para o programa Jogo de Ideias, gravado em agosto de 2008, no Bar do Zé Batidão, em São Paulo/SP. São Paulo, 15 jun. Vídeo. Disponível em: <https://goo.gl/fxStFK>. Acesso em: 26 ago. 2015.

KINTÊ, Akins (2014). Duro não é o cabelo. Participação do poeta Akins Kinte no show do Aláfia. São Paulo, 30 set. Vídeo. Disponível em: <https://goo.gl/3Jv2XR>. Acesso em: 15 ago. 2015.

MENDES, Cleyton (2015). Apresentação no Sarau Suburbano Convicto. São Paulo, ago. Vídeo. Disponível em: <https://goo.gl/vrHfQp>. Acesso em: 25 ago. 2015.

MINCHONI, Daniel (2014a). Literatura ostentação. Produção musical de Thiago França e Daniel Toledo. Vídeo. Disponível em: <https://goo.gl/Bk3AWz>. Acesso em: 28 ago. 2015.

MINCHONI, Daniel (2014b). Sola: a poesia como esporte nacional. Entrevista a Regina Azevedo. O Chaplin, 2 jan. Disponível em: <http://goo.gl/uywlPY>. Acesso em: 11 set. 2015.

NASCIMENTO, Érica Peçanha do (2009). Vozes marginais na literatura. Rio de Janeiro: Aeroplano.

NOVAES, Regina (2006). Os jovem de hoje: contextos, diferenças e trajetórias. In ALMEIDA, Maria Isabel M. de; EUGENIO, Fernanda (Org.). Culturas jovens: novos mapas do afeto. Rio de Janeiro: Zahar, p. 105-120.

PATROCÍNIO, Paulo Roberto Tonani do (2013). Escritos à margem: a presença de autores de periferia na cena literária brasileira. Rio de Janeiro: FAPERJ; 7Letras.

POETAS AMBULANTES (s.d.). Descrição do blog do coletivo Poetas Ambulantes. São Paulo. On-line. Disponível em: <http://goo.gl/UTDNO4>. Acesso em: 22 ago. 2015.

RACIONAIS MC's (2002). Negro drama. In: RACIONAIS MC's. Nada como um dia após o outro. São Paulo: Cosa Nostra. CD.

RODRIGUEZ, Bryan (2015). Somos una sola raza. Slam Resistência - 07/2015. São Paulo, 23 jul. Vídeo. Disponível em: <https://goo.gl/mCSLZV>. Acesso em: 20 jul. 2015. A letra do poema foi gentilmente enviada por Bryan Rodriguez por e-mail.

SCHECHNER, Richard (2006). Performance studies: an introduction. New York: Routledge.

SHABAZZ, Dugueto (2007). Volta pro condomínio. Blog de Cidinha da Silva, 8 ago. 2007. On-line. Disponível em: <http://goo.gl/hHmsMM>. Acesso em: $1^{\circ}$ set. 2015. 
SHABAZZ, Dugueto (2011). Eu vi ela. Apresentação no Sarau do Binho em 21 fev. 11. São Paulo, 23 fev. 2011. Vídeo. Disponível em: <https://goo.gl/67UzSt>. Acesso em: 12 set. 2015.

SILVA, José Carlos G. da (2012). Do hip-hop ao Sarau Vila Fundão: jovens, música e poesia na cidade de São Paulo. Cadernos de Arte e Antropologia, Salvador, v. 1, n. 2, p. 39-54.

SOARES, Luiz Eduardo (2006). O futuro como passado e o passado como futuro. In ALMEIDA, Maria Isabel M. de; EUGENIO, Fernanda (Org.). Culturas jovens: novos mapas do afeto. Rio de Janeiro: Zahar, p. 120-135.

SOMERS-WILLETT, Susan B. A. (2009). The cultural politics of slam poetry. Ann Arbor: University of Michigan Press.

STELLA, Marcello G. P. (2015). A Batalha da Poesia... O slam da Guilhermina e os campeonatos de poesia falada em São Paulo. Ponto Urbe, São Paulo, n. 17, p. 1-15.

TENNINA, Lucía (2013). Saraus das periferias de São Paulo: poesia entre tragos, silêncios e aplausos. Estudos de literatura brasileira contemporânea, n. 42, p. 11-28, jul./dez. 2013.

VAZ, Sérgio (2008). Cooperifa: antropofagia periférica. Rio de Janeiro: Aeroplano. ZUMTHOR, Paul (1997). Introdução à poesia oral. São Paulo: Hucitec.

Recebido em outubro de 2015.

Aprovado em março de 2016.

\section{resumo/abstract/resumen}

\section{Poesia ao vivo: algumas implicações políticas e estéticas da cena literária nas quebradas de São Paulo}

\section{Carlos Cortez Minchillo}

Este artigo é resultado da observação recente da cena literária dos saraus e slams de poesia na cidade de São Paulo. Organizados e frequentados especialmente por jovens de classes economicamente menos privilegiadas de regiões pobres e periféricas da cidade, saraus literários e slams de poesia sugerem interessantes questões de natureza política, ética e estética. Defendo que esses eventos em que predomina a performance de poesia são potencialmente revolucionários não apenas pelas mensagens de contestação e ameaça que muitos textos, flagrantemente inspirados pela cultura hip-hop, veiculam, mas, sobretudo, pelo modo como eles são apresentados e pela rede de sociabilidade "marginal" que eles ajudam a 
estabelecer. Atrelados ao movimento maior de fortalecimento das vozes subalternas na sociedade brasileira, slams e saraus têm contribuído para a construção de discursos contra-hegemônicos que potencialmente desestabilizam representações sociais cristalizadas. Ao mesmo tempo, desafiam noções amplamente aceitas sobre o que é literatura, como ela é produzida e difundida.

Palavras-chave: literatura marginal, sarau, slams de poesia, circulação da literatura.

\section{Live poetry: some aesthetic and political implications of the literary scene in the hoods of São Paulo}

\section{Carlos Cortez Minchillo}

This article is the result of recent observations of the marginal literary scene of São Paulo. Interesting political, ethical and aesthetic issues arise from the study of literary salons and poetry slams organized and attended especially by economically underprivileged young people in peripheral, poor areas of the city. I argue that these events, in which poetry is performed, are potentially revolutionary not only because of the messages of social revolt and political menace conveyed by texts which are greatly influenced by hip-hop culture, but also for the way they are performed as well as the alternative social networks these events help to establish. Linked to the broader process of empowering subaltern voices in Brazilian society, slams and literary salons in poor areas are contributing to the creation of counter-hegemonic discourses that may deconstruct crystallized social representations. At the same time, they may challenge widely accepted ideas about what literature is, and how it is produced and delivered.

Keywords: marginal literature, literary salons, slam poetry, literary circulation.

\section{Poesía en vivo: algunas implicaciones políticas y estéticas de la escena literaria en los barrios de la periferia de São Paulo}

\section{Carlos Cortez Minchillo}

Este artículo resulta de una reciente observación de la escena literaria marginal de São Paulo. Organizada y frecuentada sobre todo por los jóvenes de las clases menos favorecidas de las zonas periféricas y pobres de la ciudad, los saraus y slams que conforman esta escena plantean interesantes preguntas de naturaleza política, ética y estética. Sostengo que esos eventos en los cuales la poesía es presentada en vivo son potencialmente revolucionarios no sólo por los mensajes de revuelta social e intimidación política expresados por unos textos principalmente influenciados por el hip hop, sino también por el modo en que son ejecutados $\mathrm{y}$ por la red social alternativa que los eventos ayudan a 
establecer. Parte del proceso más amplio de empoderamiento de las voces subalternas en la sociedad brasileña, los slams y los saraus literarios en zonas pobres contribuyen a generar discursos contra-hegemónicos que pueden desestabilizar las representaciones sociales cristalizadas. Al mismo tiempo, pueden cuestionar ideas ampliamente aceptadas sobre lo que es la literatura, cómo es producida y distribuida.

Palabras clave: literatura marginal, sarau literario, slam poetry, circulación literaria. 